DOI:10.2478/rrlm-2018-0034

\title{
Associations of vascular calcification, calcium phosphate disturbances, FGF 23 and Matrix Gla protein with mortality of hemodialysis patients: one center cohort study
}

\author{
Vaida Petrauskiene $^{1 *}$, Ruta Vaiciuniene ${ }^{1}$, Vytautas Kuzminskis ${ }^{1}$, \\ Edita Ziginskiene', Saulius Grazulis ${ }^{1}$, Egle Jonaitiene ${ }^{2}$, Erika Skrodeniene ${ }^{3}$, \\ Inga Arune Bumblyte ${ }^{1}$
}

1. Department of Nephrology, Medical Academy, Lithuanian University of Health Sciences, Lithuania 2. Department of Radiology, Medical Academy, Lithuanian University of Health Sciences, Lithuania 3. Department of Laboratory medicine, Medical Academy, Lithuanian University of Health Sciences, Lithuania

\begin{abstract}
Background and objectives: Vascular calcification (VC) is one of the factors associated with mortality in hemodialysis (HD) patients. The purpose of the study was to assess associations between prevalent VC and disturbances of calcium-phosphate metabolism as well as changes in vitamin D (25(OH)D), FGF 23 and MGP levels and to evaluate the possible impact of VC and changes of these biomarkers on survival in HD patients. Methods: The study population consisted of 81 prevalent patients in the hemodialysis unit of Hospital of Lithuanian University of Health Sciences Kaunas Clinics. A simple vascular calcification score (SVCS) was evaluated as it is described by Adragao et al. 25(OH)D (nmol/L), FGF $23(\mathrm{ng} / \mathrm{L})$ and $M G P(\mathrm{ng} / \mathrm{mL})$ were measured and analysed. Results: Patients were divided into two groups: SVCS $<3$ (31 patient (38.3\%) and SVCS $\geq 3$ (50 patients (61.7\%)). In multivariate logistic regression, age (odds ratio 1.062, 95\% CI [1.024-1.1] $p=0.001$ ) and diabetes (odds ratio 6.9, $95 \%$ CI [1.5-31], $p=0.012$ ) were associated with $S V C S \geq 3$. The multivariate logistic regression revealed the highest negative impact of SVCS $\geq 3$, age and 25(OH)D level for death risk. Conclusion: VC in HD patients is highly influenced by age and presence of diabetes and associated with higher risk of death. No significant association was found between MGP and FGF 23 and VC as well as between these two biomarkers and risk of death. Lower $25(\mathrm{OH}) D$ levels were associated with mortality in this dialysis patients cohort.
\end{abstract}

Keywords: mineral metabolism disorders; FGF 23; MGP; hemodialysis, survival

Received: $2^{\text {nd }}$ August 2018; Accepted: 25 ${ }^{\text {th }}$ September 2018; Published: $9^{\text {th }}$ October 2018

* Corresponding author: Vaida Petrauskienè. Department of Nephrology, Medical Academy, Lithuanian University of Health Sciences, Kaunas, Lithuania

E-mail: vaida.petrauskiene@gmail.com 


\section{Introduction}

Chronic kidney disease is an independent risk factor for cardiovascular diseases even from its early stages (1). Cardiovascular diseases dependent death risk in dialysis patients is significantly higher compared to general population $(2,3)$. This increased risk can not be attributed only to traditional cardiovascular risk factors (4-6). One of the specific factors associated with mortality in hemodialysis (HD) patients in particular is vascular calcification (VC) $(7,8)$. Despite the well known negative impact of atherosclerosis causing intima lesions, media calcification is known to be a specific injury for HD patients affecting hemodynamics significantly and contributing to negative outcomes as well (9).

Media calcification, as well as increased cardiovascular risk, has long been related to calcium (Ca)-phosphorus (P) metabolism disorders. Hyperphosphatemia is important in process of osteoblastic transformation of smooth muscle cells in the vessel wall as well as mineral deposition $(8,10)$. In addition, vitamin $\mathrm{D}$ $(25(\mathrm{OH}) \mathrm{D})$ deficiency together with secondary hyperparathyroidism and hyperphosphatemia were considered as the main factors contributing to cardiovascular risk in renal patients (1113). VC used to be described only as a passive process earlier. Lately many studies proved that it is an actively regulated process dependent on calcification promoters and inhibitors. One of the pivotal calcification inhibitors is Matrix Gla protein (MGP). An inverse association between total uncarboxylated MGP and VC in HD patients was demonstrated $(14,15)$. Independent associations of MGP and arterial calcification as well as carotid atherosclerosis in patients without kidney disease were also presented in a study of Sitar Taut A. and coauthors (16). Moreover, lower levels of circulating MGP were found to be a predictor of mortality in HD patients (17).
In addition to that fact, several studies revealed an independent association between mortality of chronic kidney disease patients and increased levels of another biomarker-Fibroblast Growth Factor 23 (FGF 23) (18,19). FGF 23 was also presented as an independent biomarker of VC, it's progression and cardiovascular diseases of HD patients $(20,21)$. Though the golden standard for detection of $\mathrm{VC}$ is electron beam or multislice computed tomography (22), the use of plain radiography is recommended in KDOQI guidelines for $\mathrm{VC}$ assessment as an adequate replacement (23). After introducing to practice the $\mathrm{VC}$ evaluation for prevalent $\mathrm{HD}$ patients, we investigated relationships of VC with disturbances of Ca-P metabolism and levels of 25(OH)D, FGF23 and MGP.

We hypothesized that higher FGF 23, lower MGP would be associated with more pronounced $\mathrm{VC}$ and mortality of HD patients. In order not to underestimate the role of Ca-P disorders, vitamin $\mathrm{D}$ deficiency, these parameters were also evaluated in complex.

\section{Methods}

The observational cohort study population consisted of prevalent patients (n-95) on maintenance HD in the dialysis unit of Hospital of Lithuanian University of Health Sciences Kaunas Clinics. The study was approved by Kaunas Regional Biomedical Research Ethics Committee (protocol number BE-2-9, 201312 02) and the informed consent was obtained from all study participants. 14 patients were excluded from analysis. Their blood samples after evaluation of VC were not obtained, as they moved to continue HD in other center or were transplanted. Data of 81 patient was analysed.

The collection and processing of demographic, clinical and laboratory data is described in details in previous published work of our group (24). 
Simple vascular calcification score (SVCS) was evaluated as it is described by Adragao et al. with SVCS $\geq 3$ considered as cut off value (25) and the methodology is presented in details in our previous research article as well (24).

Blood samples for measurements of FGF 23, MGP and 25(OH)D were collected as SVCS was evaluated. Patients were observed until the end of May 2017. Mean follow up - 1058.8 days (23-1560 days).

Human FGF 23 ELISA Kit (Sunlong Biotech, Zhejiang China) and Human MGP ELISA Kit (Sunlong Biotech, Zhejiang China) were used for analysis of FGF 23 and MGP accordingly. Measurement and analysis of both results were done using immunoassay ELISA analyzer Gemini (Stratec Biomedical GmbH, Birkenfeld, Germany). Methods of measurements of serum biochemical parameters are presented in previous work of the group (24).

For discrete factors variables were expressed as frequencies, percentages. Based on the normality of data distribution of continuous factors, median [minimal-maximal values] or means with standard deviation were used. We performed statistical comparison using the two-tailed chisquare test for categorical variables and twotailed Student's T-test or Mann-Whitney test for continuous variables were appropriate. For survival analysis, the Kaplan-Meier survival curves of patients with $\mathrm{SVCS} \geq 3$ and $<3$ were compared by log-rank test.

To identify clinical factors and laboratory changes that may be important for severe VC (SVCS $\geq 3$ ), odds ratios obtained from univariate and multivariate binary logistic regression were used. Independent variable was severe VC (SVCS $\geq 3$ ), dependent variables were age, gender, diabetes, HD vintage, 25(OH)D, FGF 23, MGP, biochemical paramethers reflecting $\mathrm{Ca}-\mathrm{P}$ disturbances at the start of dialysis and at the moment of evaluation of SVCS. Regressors that statistically significantly prognosed severe VC in univariate analysis, were included in a multivariate binary logistic model. To assess possible associations between survival rate and $\mathrm{VC}$ as well as age, presence of diabetes, HD vintage, FGF23 and MGP levels as well as 25(OH)D we also performed univariate and multivariate binary logistic regression analysis. For comparison a $P$ value $<0.05$ was considered significant. IBM SPSS statistics 24.0 software package for statistical analysis was used.

\section{Results}

SVCS was evaluated in 44 men $(54.3 \%)$ and 37 women (45.7\%). 17 (21\%) had diagnosed diabetes. The mean age was $60.9 \pm 16.01$ (22$86)$ and the mean HD duration of all patients included 39.26 \pm 46.24 months (1-182). 23 patients $(28.4 \%)$ were treated with alfacalcidol. 49 (60.5\%) received $\mathrm{Ca}$ acetate/ $\mathrm{Mg}$ subcarbonate (Osvaren) and 30 (37\%) Ca carbonate as a phosphate binder.

SVCS $<3$ was observed in 31 patient (38.3\%) and SVCS $\geq 3$ in 50 patients $(61.7 \%)$. Comparison of clinical and demographical profiles is presented in Table 1. The prevalence of diabetes was significantly higher in the group with SVCS $\geq 3$. Patients in this group were significantly older as well (Table 1).

There was a trend to higher values of serum $\mathrm{P}$, alkaline phosphatase (ALP) and $\mathrm{C}$ reactive protein (CRP) in the group with $\mathrm{SVCS} \geq 3$ at the start of HD treatment, but the differences didn't reach the level of significance. At the moment of evaluation of SVCS, patients with $\mathrm{SVCS} \geq 3$ had statistically significant lower $\mathrm{Kt} / \mathrm{V}$ value, but other biochemical parameters didn't differ significantly, though higher levels of serum $\mathrm{P}$ and ALP remained observed. No statistically significant differences were observed comparing FGF23 and MGP levels between the groups with different SVCS (Table 2). 
Table 1. Demographic and clinical information in groups with different simple vascular calcification score

\begin{tabular}{lccc}
\hline & SVCS $<\mathbf{3}$ & SVCS $\geq \mathbf{3}$ & Significance (p) \\
\hline Participants (n) & 31 & 50 & \\
\hline Age, mean (SD), years & $53.97(16.2)$ & $65.2(14.4)$ & 0.002 \\
\hline HD vintage, mean (SD), months & $34.23(33.19)$ & $42.38(52.8)$ & $\mathrm{p}>0.05$ \\
\hline BMI, mean (SD), $\mathrm{kg} / \mathrm{m}^{2}$ & $24.7(4.7)$ & $25.8(5.0)$ & $\mathrm{p}>0.05$ \\
\hline Diabetes, $\mathrm{n}(\%)$ & $3(9.6)$ & $14(28)$ & 0.05 \\
\hline Hypertension, $\mathrm{n}(\%)$ & $29(93.5)$ & $45(90)$ & $\mathrm{p}>0.05$ \\
\hline Cardiovascular Disease, $\mathrm{n}(\%)$ & $13(41.9)$ & $29(58)$ & $\mathrm{p}>0.05$ \\
\hline Gender, $\mathrm{n}(\%)$ & & & \\
Female & $14(45.16)$ & $23(46)$ & $\mathrm{p}>0.05$ \\
Male & $17(54.8)$ & $27(54)$ & $\mathrm{p}>0.05$ \\
\hline Treatment & & & \\
Alfacalcidol, $\mathrm{n}(\%)$ & $12(38.7)$ & $11(22)$ & $\mathrm{p}>0.05$ \\
Calcium carbonate, $\mathrm{n}(\%)$ & $14(45.2)$ & $16(32)$ & $\mathrm{p}>0.05$ \\
Ca acetate/Mg subcarbonate, $\mathrm{n}(\%)$ & $18(58.1)$ & $31(62)$ & $\mathrm{p}>0.05$ \\
\hline
\end{tabular}

Results in mean values (SD) or n (\%); SVCS-simple vascular calcification score; Two-tailed chi-square test for categorical variables and twotailed Student‘s T-test for continues variables was used

Table 2. Biochemical parameters of the hemodialysis patients begining hemodialysis and at the moment of radiological evaluation

\begin{tabular}{|c|c|c|c|}
\hline & SVCS $<3$ (n-31) & SVCS $\geq 3(n-50)$ & Significance $(p)$ \\
\hline \multicolumn{4}{|c|}{ Begining of hemodialysis } \\
\hline $\mathrm{Ca}(\mathrm{mmol} / \mathrm{L})$ & $2.09(0.24)$ & $2.09(0.21)$ & $p>0.05$ \\
\hline $\mathrm{P}(\mathrm{mmol} / \mathrm{L})$ & $1.59(0.59)$ & $1.71(0.58)$ & $\mathrm{p}>0.05$ \\
\hline $\mathrm{Ca} \times \mathrm{P}\left(\mathrm{mmol} / \mathrm{L}^{2}\right)$ & $3.34(1.37)$ & $3.59(1.3)$ & $\mathrm{p}>0.05$ \\
\hline iPTH (pmol/L) & $40.9(35.2)$ & $44.8(33.7)$ & $\mathrm{p}>0.05$ \\
\hline $\operatorname{ALP}(\mathrm{U} / \mathrm{L})$ & $78.8(42.8)$ & $108.76(125.9)$ & $\mathrm{p}>0.05$ \\
\hline $\mathrm{Kt} / \mathrm{V}$ & $1.28(0.28)$ & $1.24(0.32)$ & $\mathrm{p}>0.05$ \\
\hline $\mathrm{Hb}(\mathrm{g} / \mathrm{L})$ & $91.45(16.8)$ & $90.61(13.9)$ & $\mathrm{p}>0.05$ \\
\hline CRP (mg/L) & $9.31(19.32)$ & $20.39(46)$ & $\mathrm{p}>0.05$ \\
\hline Cholesterol $(\mathrm{mmol} / \mathrm{L})$ & $5.01(1.32)$ & $4.9(1.52)$ & $\mathrm{p}>0.05$ \\
\hline Albumin $(\mathrm{g} / \mathrm{L})$ & $34.6(5.6)$ & $33.0(5.9)$ & $\mathrm{p}>0.05$ \\
\hline \multicolumn{4}{|c|}{ Radiological evaluation moment } \\
\hline $\mathrm{Ca}(\mathrm{mmol} / \mathrm{L})$ & $2.21(0.18)$ & $2.19(0.21)$ & $\mathrm{p}>0.05$ \\
\hline $\mathrm{P}(\mathrm{mmol} / \mathrm{L})$ & $1.67(0.55)$ & $1.88(0.54)$ & $\mathrm{p}>0.05$ \\
\hline $\mathrm{Ca} \times \mathrm{P}\left(\mathrm{mmol} / \mathrm{L}^{2}\right)$ & $3.7(1.3)$ & $4.06(1.3)$ & $\mathrm{p}>0.05$ \\
\hline iPTH (pmol/L) & $46.8(39.48)$ & $47.45(44.60)$ & $\mathrm{p}>0.05$ \\
\hline $\operatorname{ALP}(\mathrm{U} / \mathrm{L})$ & $77.96(35.5)$ & $106.8(193.2)$ & $\mathrm{p}>0.05$ \\
\hline $\mathrm{Kt} / \mathrm{V}$ & $1.52(0.27)$ & $1.37(0.24)$ & 0.02 \\
\hline $\mathrm{Hb}(\mathrm{g} / \mathrm{L})$ & $110(14.2)$ & $108(13.2)$ & $\mathrm{p}>0.05$ \\
\hline $\mathrm{CRP}(\mathrm{mg} / \mathrm{L})$ & $8.11(12.5)$ & $12.7(24.4)$ & $\mathrm{p}>0.05$ \\
\hline Cholesterol $(\mathrm{mmol} / \mathrm{L})$ & $4.9(1.47)$ & $5.1(1.2)$ & $\mathrm{p}>0.05$ \\
\hline Albumin $(\mathrm{g} / \mathrm{L})$ & $35.5(3.7)$ & $34(3.6)$ & $\mathrm{p}>0.05$ \\
\hline $25(\mathrm{OH}) \mathrm{D}(\mathrm{nmol} / \mathrm{L})$ & $46.45(19.15)$ & $37.94(17.69)$ & 0.045 \\
\hline FGF $23(\mathrm{ng} / \mathrm{L})$ & 33.34 [3.36-199.79] & $44.76[0.00-788.99]$ & $\mathrm{p}>0.05$ \\
\hline MGP (ng/mL) & $1.66[0.7-5.96]$ & $1.6[0.41-27.43]$ & $\mathrm{p}>0.05$ \\
\hline
\end{tabular}

SVCS -simple vascular calcification score; results presented as mean values (SD); Two-tailed Student's T-test for comparison was used. Results of FGF 23 and MGP presented as median [minimal-maximal values]; Mann-Whitney test used for comparison 
The mean $25(\mathrm{OH}) \mathrm{D}$ value was $41.2 \pm 18.6$ $\mathrm{nmol} / \mathrm{L}$ and ranged from 10 to $101.9 \mathrm{nmol} / 1.56$ patients $(69.1 \%)$ had severe $25(\mathrm{OH}) \mathrm{D}$ deficiency with $25(\mathrm{OH}) \mathrm{D}$ levels less than $50 \mathrm{nmol} / \mathrm{L}$. 19 patients $(23.5 \%)$ were vitamin D insufficient with $25(\mathrm{OH}) \mathrm{D}$ values between 51 and 69 nmo1/L. Only 6 patients $(7.4 \%)$ had $25(\mathrm{OH}) \mathrm{D}$ values over $70 \mathrm{nmol} / \mathrm{L}$. 25(OH)D values within the groups with different SVCS are presented in Table 2. Patients with severe VC had significantly lower 25(OH)D levels.

In univariate logistic regression, age and diabetes but not 25(OH)D, FGF23, MGP or Ca-P disturbances were associated with SVCS $\geq 3$ (Table 3). For multivariate binary logistic regression, only statistically significant factors were included. The influence of age, for severe VC remained stable with OR 1.062 [1.025-1.1], $\mathrm{p}=0.001$ and the importance of diabetes even increased with OR 6.9 [1.5-31], $\mathrm{p}=0.012$.

During the observational period, 22 deaths occurred. The Kaplan - Meier analysis revealed a tendency for higher risk of death for patients with more severe VC (SVCS $\geq 3$ vs $\operatorname{SVCS}<3$ $(40 \%$ vs 6.5\%, log rank 10.96, $\mathrm{p}=0.001)$ ) (Fig 1).

To assess possible associations between survival rate and $\mathrm{VC}$, age, the presence of diabetes, HD vintage as well as FGF 23, MGP and 25(OH) $\mathrm{D}$ levels we performed univariate and multivariate logistic regression analysis and results are presented in Table 4 and Table 5. For multivariate binary logistic regression, only statistically significant factors were included and it revealed the highest negative impact of severe $\mathrm{VC}$ with SVCS $\geq 3$ for death risk of studied HD patients. Age and 25(OH)D, but not HD vintage remained important as well.

\section{Discussion}

The results of the study confirm the high prevalence of $\mathrm{VC}$ in HD patients. It also demonstrates the contribution of $\mathrm{VC}$ on mortality of HD patients.

Remarkably, in our cohort, only age and presence of diabetes were associated with higher scores of $\mathrm{VC}$, but neither biomarkers reflecting

Table 3. Risk factors for vascular calcification: univariate analysis

\begin{tabular}{|c|c|c|c|}
\hline Independent variable & OR & 95 proc. $\mathrm{CI}$ & Significance (p) \\
\hline Age, years & 1.062 & 1.024-1.1 & 0.001 \\
\hline Male & 1.07 & $0.469-2.46$ & 0.866 \\
\hline Diabetes mellitus & 5.4 & $1.17-24.9$ & 0.03 \\
\hline HD vintage, month & 1.007 & $0.99-1.01$ & 0.071 \\
\hline FGF 23 (ng/L) & 1.004 & $0.996-1.013$ & 0.321 \\
\hline MGP (ng/mL) & 1.105 & $0.854-1.430$ & 0.447 \\
\hline $25(\mathrm{OH}) \mathrm{D}(\mathrm{nmol} / \mathrm{L})$ & 0.975 & $0.951-1.0$ & 0.51 \\
\hline \multicolumn{4}{|c|}{ Begining of hemodialysis } \\
\hline $\mathrm{Ca}(\mathrm{mmol} / \mathrm{L})$ & 0.99 & $0.137-7.2$ & 0.998 \\
\hline $\mathrm{Ca}$ ion $(\mathrm{mmol} / \mathrm{L})$ & 0.233 & $0.61-5.9$ & 0.373 \\
\hline $\mathrm{P}(\mathrm{mmol} / \mathrm{L})$ & 1.437 & $0.647-3.19$ & 0.373 \\
\hline $\mathrm{Ca} \times \mathrm{P}\left(\mathrm{mmol} / \mathrm{L}^{2}\right)$ & 1.16 & $0.895-1.7$ & 0.184 \\
\hline iPTH $(\mathrm{pmol} / \mathrm{L})$ & 1.003 & $0.99-1.017$ & 0.617 \\
\hline \multicolumn{4}{|c|}{ Radiological evaluation moment } \\
\hline $\mathrm{Ca}(\mathrm{mmol} / \mathrm{L})$ & 0.671 & $0.07-6.397$ & 0.729 \\
\hline $\mathrm{Ca}$ ion $(\mathrm{mmol} / \mathrm{L})$ & 0.055 & $0.001-4.9$ & 0.205 \\
\hline $\mathrm{P}(\mathrm{mmol} / \mathrm{L})$ & 1.681 & $0.725-3.89$ & 0.226 \\
\hline $\mathrm{Ca} \times \mathrm{P}\left(\mathrm{mmol} / \mathrm{L}^{2}\right)$ & 1.209 & 0.816-1.69 & 0.273 \\
\hline $\mathrm{iPTH}(\mathrm{pmol} / \mathrm{L})$ & 1.0 & $0.99-1.01$ & 0.957 \\
\hline
\end{tabular}

OR- odds ratio, $\mathrm{CI}$ - confidence interval 


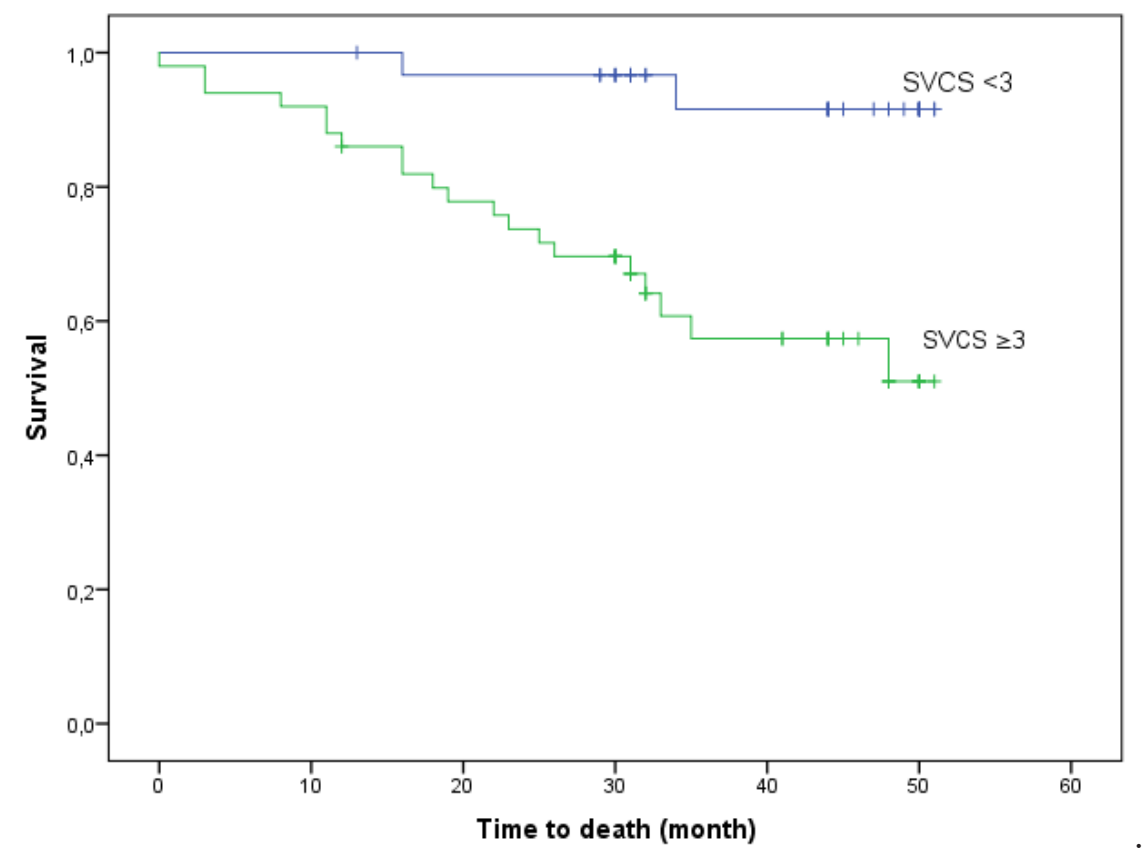

Figure 1. Survival in patients with simple vascular calcification score $<3$ and $\geq 3$

Table 4. Risk factors for death: univariate analysis

\begin{tabular}{lccc}
\hline Independent variable & OR & 95 proc. CI & Significance (p) \\
\hline SVCS $\geq 3$ & 8.804 & $2.763-28.05$ & 0.0001 \\
\hline Age & 1.064 & $1.028-1.101$ & 0.0001 \\
\hline Diabetes mellitus & 2.56 & $0.919-7.1$ & 0.072 \\
\hline HD vintage & 1.011 & $1.011-1.021$ & 0.02 \\
\hline FGF 23 & 0.991 & $0.978-1.004$ & 0.172 \\
\hline MGP & 0.532 & $0.279-1.016$ & 0.056 \\
\hline $25(\mathrm{OH}) \mathrm{D}$ & 0.950 & $0.917-0.983$ & 0.04 \\
\hline
\end{tabular}

OR-odds ratio, CI- confidence interval, SVCS -simple vascular calcification score

Table 5. Risk factors for death: multivariate analysis

\begin{tabular}{lccc}
\hline Independent variable & OR & 95 proc. CI & Significance (p) \\
\hline SVCS $\geq 3$ & 4.676 & $1.1-19.88$ & 0.037 \\
\hline Age & 1.053 & $1.009-1.1$ & 0.018 \\
\hline HD vintage & 1.05 & $0.993-1.0108$ & 0.426 \\
\hline 25OHD & 0.930 & $0.869-0.996$ & 0.038 \\
\hline
\end{tabular}

OR-odds ratio, CI- confidence interval, SVCS -simple vascular calcification score

Ca-P metabolism disturbances nor calcification biomarkers, such as FGF 23 and MGP, were not. The fact that patients with higher VC scores were older and more often had diabetes proba- bly supports the possibility of intima and media calcification co-existence, which is described by previous works $(8,26)$. Both intima and media calcification are associated with poor prognosis 
in HD patients and the principal question would be whether these different forms of vascular injury require a different treatment in everyday practice.

Media calcification, specific for dialysis patients and patients with chronic kidney disease has long been associated with disturbances of Ca- P metabolism presenting as hyperphoshatemia, hypercalcemia and higher levels of $\mathrm{Ca} \times \mathrm{P}$ product $(27,28)$. Still, recent scientific data regarding these associations remains controversial. Some authors presented the results reflecting associations between higher serum phosphate levels and calcification lessions in the arteries, the others, including author of the method of evaluation SVCS, did not $(8,25,29)$. We did not find any associations of Ca-P disturbances neither analyzing laboratory data at the start of the treatment of HD nor at the moment of evaluation of SVCS though one of our hypothesis was that patients who start treatment with severe disturbances of Ca-P metabolism present with more severe $\mathrm{VC}$ later on.

$\mathrm{VC}$ is no longer considered only as a passive degenerative process, but an actively regulated one with several biomarkers suggested as calcification promoters and inhibitors (30). MGP is a potent inhibitor of extra osseous Ca-P precipitation. It is a vit $\mathrm{K}$ dependent cyclin and it's activation requires $\gamma$ carboxylation. MGP acts as calcification inhibitor in vivo inhibiting Ca precipitation and crystallization in the vessel wall (31).

Data on the role of MGP changes in a uremic state is still inconclusive. Several studies have reported significantly lower serum levels of uncarboxylated MGP in dialysis patients than healthy controls (32). In others, markedly elevated plasma levels of MGP were found as compared to healthy controls probably due to impaired MGP activation, increased production and release as well as decreased clearance of MGP in HD patients (17). In our study, the levels of MGP were higher compared to those presented in the study of Xiao et al. (32) though both studies evaluated overall serum MGP. We did not find any significant difference in MGP levels of patients with different $\mathrm{VC}$ severity. It is demonstrated in the literature that higher FGF 23 levels and lower uncarboxylated MGP levels are associated with mortality and cardiovascular events in patients without end-stage renal disease (32). We also expected to find this type of associations in HD patients, but our study did not succeed to prove it and we can only speculate about the underlying mechanism of these observations. The possibility, that higher levels of MGP in HD patients are due to impaired activation in vessel wall because of deficit of vit $\mathrm{K}$, may be one of the explanations. Results of the observational study of prevalent HD patient performed by Delanaye et al. would not contradict the hypothesis. Higher concentrations of inactive dp-ucMGP were found in hemodialysis patients as compared to healthy controls. A significant correlation between inactive MGP level and calcification score was confirmed both by univariate and multivariate analysis (33). In a study performed by Aoun $\mathrm{M}$ et al. reported that vit $\mathrm{K}$ deficiency, as assessed by high dp-ucMGP levels, is profound in HD patients of their study population and it is significantly correlated with VC. Daily supplementation of menaquinone-7 effectively reduced dp-ucMGP in this population (34).

In our study, we failed to confirm the correlation of MGP levels and VC. A limited number of patients in the study and possibility to measure only overall MGP levels could be one of the explanations.

FGF 23 is known to be elevated in patients with chronic kidney disease and is strongly associated with mortality and cardiovascular diseases (19,35-37) . In our study, we found relatively low values of FGF23 as compared to Xiao et al study (32) and this probably needs more detailed 
investigation to clarify the reasons. Our study failed to show statistically significant differences in FGF 23 levels in patients with different VC scores. Scialla et al. in both clinical and experimental analysis proved that elevated FGF $23 \mathrm{lev}-$ els were not consistently associated with $\mathrm{VC}$ in CKD patients. They suggest that the strong associations of elevated FGF 23 with cardiovascular events and mortality may be explained by other forms of cardiovascular injury such as FGF23 induced left ventricular hypertrophy and klothoindependent effects on cardiac myocytes, but not calcification of vessels (38). In a study by Moldovan et al. FGF-23 did not correlate with VC score as well. Interestingly, the lower FGF23 levels were identified as risk factors for cardiovascular diseases (39).

Our study also confirms the importance of vit $\mathrm{D}$ for death risk for dialysis patients but not for the presence of vascular calcification. Vitamin D deficiency is well known to be associated with high mortality as well as with several other unfavorable adverse effects in general population (40). But data about negative impact of vitamin D defficiency for HD patients is still inconclusive and there is no precise recommendations for treatment of the condition. Our study is consistent with previously published systematic review and meta-analysis of clinical studies by Zhang Y, which revealed positive associations of higher serum $25(\mathrm{OH}) \mathrm{D}$ level with lower allcause mortality and lower cardiovascular mortality in dialysis patients (41).

Limitations of our study are relatively small sample size and observational structure. We also did not have a possibility to discriminate active and inactive forms of MGP measuring only overall values. Additional evaluation of vitamin $\mathrm{K}$ status could have been interesting and important.

As it is agreed that $\mathrm{VC}$ is responsible for many negative effects for HD patients, it is crucial to find reliable tools to prevent this disorder. For years, it was believed that optimal long-term control of $\mathrm{Ca}-\mathrm{P}$ balance would play the major role in the prevention of $\mathrm{VC}$. We did not find any significant associations between $\mathrm{Ca}-\mathrm{P}$ metabolism disorders and present VC. Changes of novel biomarkers such as FGF 23 and MGP do not answer questions too.

\section{Conclusions}

In conclusion, the present study showed that vascular calcification in our cohort hemodialysis patients is highly influenced by age and presence of diabetes but neither disturbances of calcium-phosphate metabolism nor levels of FGF23, MGP or $25(\mathrm{OH}) \mathrm{D}$. Age, vascular calcification and lower levels of 25(OH)D but not FGF 23 or MGP were major factors associated with higher risk of death.

\section{Author Contributions}

VP- study design, data collection and interpretation, writing the first draft, preparation of final manuscript.

RV- data collection, statistical analysis, preparation of final manuscript.

VK- study design, data interpretation, preparation of final manuscript.

EZ- study design, data collection, preparation of final manuscript.

SG- data collection, statistical analysis, preparation of final manuscript.

EJ- radiological data analysis, preparation of final manuscript.

ES- performed imunoassays, preparation of final manuscript.

IAB- study design, data interpretation, preparation of final manuscript.

\section{Conflicts of Interest}

The authors declare that they have no conflicts of interests. 


\section{References}

1. Go AS, Chertow GM, Fan D, McCulloch CE, Hsu CY. Chronic kidney disease and the risks of death, cardiovascular events, and hospitalization. $\mathrm{N}$ Engl J Med 2004 Sep 23;351(13):1296-1305. DOI: 10.1056/NEJMoa041031

2. Foley RN, Parfrey PS. Cardiovascular disease and mortality in ESRD. J Nephrol 1998 Sep-Oct;11(5):239-45.

3. Collins AJ, Foley RN, Chavers B, Gilbertson D, Herzog C, Ishani A, et al. US Renal Data System 2013 Annual Data Report. Am J Kidney Dis 2014 Jan;63(1 Suppl):A7. DOI: 10.1053/j.ajkd.2013.11.001

4. Foley RN, Parfrey PS, Sarnak MJ. Clinical epidemiology of cardiovascular disease in chronic renal disease. Am J Kidney Dis 1998 Nov;32(5 Suppl 3):S112-9. DOI: 10.1053/ajkd.1998.v32.pm9820470

5. Herzog CA, Ma JZ, Collins AJ. Poor long-term survival after acute myocardial infarction among patients on long-term dialysis. N Engl J Med 1998 Sep 17;339(12):799-805. DOI: 10.1056/ NEJM199809173391203

6. Moe S, Drueke T, Cunningham J, Goodman W, Martin $\mathrm{K}$, Olgaard K, et al. Definition, evaluation, and classification of renal osteodystrophy: a position statement from Kidney Disease: Improving Global Outcomes (KDIGO). Kidney Int 2006 Jun;69(11):1945-53. DOI: 10.1038/sj.ki.5000414

7. Blacher J, Guerin AP, Pannier B, Marchais SJ, London GM. Arterial calcifications, arterial stiffness, and cardiovascular risk in end-stage renal disease. Hypertension 2001 Oct;38(4):938-42. DOI: 10.1161/ hy 1001.096358

8. London GM, Guerin AP, Marchais SJ, Metivier F, Pannier B, Adda H. Arterial media calcification in end-stage renal disease: impact on all-cause and cardiovascular mortality. Nephrol Dial Transplant 2003 Sep;18(9):1731-40. DOI: 10.1093/ndt/gfg414

9. Shanahan CM, Cary NR, Salisbury JR, Proudfoot D, Weissberg PL, Edmonds ME. Medial localization of mineralization-regulating proteins in association with Monckeberg's sclerosis: evidence for smooth muscle cell-mediated vascular calcification. Circulation 1999 Nov 23;100(21):2168-76. DOI: 10.1161/01. CIR.100.21.2168

10. Steitz SA, Speer MY, Curinga G, Yang HY, Haynes $\mathrm{P}$, Aebersold R, et al. Smooth muscle cell phenotypic transition associated with calcification: upregulation of Cbfal and downregulation of smooth muscle lineage markers. Circ Res 2001 Dec 7;89(12):1147-54. DOI: $10.1161 / \mathrm{hh} 2401.101070$

11. Bhuriya R, Li S, Chen SC, McCullough PA, Bakris GL. Plasma parathyroid hormone level and prevalent cardiovascular disease in CKD stages 3 and 4: an analysis from the Kidney Early Evaluation Pro- gram (KEEP). Am J Kidney Dis 2009 Apr;53(4 Suppl 4):S3-10. DOI: 10.1053/j.ajkd.2008.11.029

12. Kimata N, Albert JM, Akiba T, Yamazaki S, Kawaguchi T, Fukuhara S, et al. Association of mineral metabolism factors with all-cause and cardiovascular mortality in hemodialysis patients: the Japan dialysis outcomes and practice patterns study. Hemodial Int 2007 Jul;11(3):340-8. DOI: 10.1111/j.15424758.2007.00190.x

13. Wolf M, Thadhani R. Vitamin D in patients with renal failure: a summary of observational mortality studies and steps moving forward. J Steroid Biochem Mol Biol 2007 Mar;103(3-5):487-90. DOI: 10.1016/j. jsbmb.2006.11.009

14. Hermans MM, Vermeer C, Kooman JP, Brandenburg V, Ketteler M, Gladziwa U, et al. Undercarboxylated matrix GLA protein levels are decreased in dialysis patients and related to parameters of calcium-phosphate metabolism and aortic augmentation index. Blood $\mathrm{Pu}$ rif 2007;25(5-6):395-401. DOI: 10.1159/000108629

15. Cranenburg EC, Vermeer C, Koos R, Boumans ML, Hackeng TM, Bouwman FG, et al. The circulating inactive form of matrix Gla Protein (ucMGP) as a biomarker for cardiovascular calcification. J Vasc Res 2008;45(5):427-36. DOI: 10.1159/000124863

16. Pop D, Sitar-Taut A, Gligor E, Bodizs G, Cebanu M, Buduru S, et al. The relationship between matrix GLA protein (MGP) and carotid stenosis. Rev Romana Med Lab 2011;19(2):169-75.

17. Schlieper G, Westenfeld R, Kruger T, Cranenburg EC, Magdeleyns EJ, Brandenburg VM, et al. Circulating nonphosphorylated carboxylated matrix gla protein predicts survival in ESRD. J Am Soc Nephrol 2011 Feb;22(2):387-95. DOI: 10.1681/ASN.2010040339

18. Gutierrez OM, Mannstadt M, Isakova T, Rauh-Hain JA, Tamez H, Shah A, et al. Fibroblast growth factor 23 and mortality among patients undergoing hemodialysis. N Engl J Med 2008 Aug 7;359(6):584-92. DOI: 10.1056/NEJMoa0706130

19. Isakova T. Fibroblast growth factor 23 and adverse clinical outcomes in chronic kidney disease. Curr Opin Nephrol Hypertens 2012 May;21(3):334-40. DOI: 10.1097/MNH.0b013e328351a391

20. Desjardins L, Liabeuf S, Renard C, Lenglet A, Lemke HD, Choukroun G, et al. FGF23 is independently associated with vascular calcification but not bone mineral density in patients at various CKD stages. Osteoporos Int 2012 Jul;23(7):2017-25. DOI: 10.1007/ s00198-011-1838-0

21. Inaba $\mathrm{M}$, Okuno $\mathrm{S}$, Imanishi $\mathrm{Y}$, Yamada $\mathrm{S}$, Shioi $\mathrm{A}$, Yamakawa T, et al. Role of fibroblast growth factor-23 in peripheral vascular calcification in non-diabetic and diabetic hemodialysis patients. Osteoporos Int 2006 Oct;17(10):1506-13. DOI: 10.1007/s00198-006-01546 
22. Braun J, Oldendorf M, Moshage W, Heidler R, Zeitler E, Luft FC. Electron beam computed tomography in the evaluation of cardiac calcification in chronic dialysis patients. Am J Kidney Dis 1996 Mar;27(3):394401. DOI: 10.1016/S0272-6386(96)90363-7

23. National Kidney Foundation. K/DOQI clinical practice guidelines for bone metabolism and disease in chronic kidney disease. Am J Kidney Dis 2003 Oct;42(4 Suppl 3):S1-201.

24. Petrauskiene V, Vaiciuniene R, Bumblyte IA, Kuzminskis V, Ziginskiene E, Grazulis S, et al. Association between vascular calcification assessed by simple radiography and non-fatal cardiovascular events in hemodialysis patients. Nephrol Ther 2016 Dec;12(7):503-7. DOI: 10.1016/j.nephro.2016.06.005

25. Adragao T, Pires A, Lucas C, Birne R, Magalhaes L, Goncalves $\mathrm{M}$, et al. A simple vascular calcification score predicts cardiovascular risk in haemodialysis patients. Nephrol Dial Transplant 2004 Jun;19(6):14808. DOI: $10.1093 /$ ndt/gfh217

26. Kurnatowska I, Grzelak P, Stefanczyk L, Nowicki M. Tight relations between coronary calcification and atherosclerotic lesions in the carotid artery in chronic dialysis patients. Nephrology (Carlton) 2010 Mar;15(2):184-9. DOI: 10.1111/j.14401797.2009.01169.x

27. Shanahan CM, Crouthamel MH, Kapustin A, Giachelli CM. Arterial calcification in chronic kidney disease: key roles for calcium and phosphate. Circ Res 2011 Sep 2;109(6):697-711. DOI: 10.1161/CIRCRESAHA.110.234914

28. El-Abbadi MM, Pai AS, Leaf EM, Yang HY, Bartley BA, Quan KK, et al. Phosphate feeding induces arterial medial calcification in uremic mice: role of serum phosphorus, fibroblast growth factor-23, and osteopontin. Kidney Int 2009 Jun;75(12):1297-307. DOI: 10.1038/ki.2009.83

29. Liabeuf S, Okazaki H, Desjardins L, Fliser D, Goldsmith D, Covic A, et al. Vascular calcification in chronic kidney disease: are biomarkers useful for probing the pathobiology and the health risks of this process in the clinical scenario? Nephrol Dial Transplant 2014 Jul;29(7):1275-84. DOI: 10.1093/ndt/gft368

30. Shanahan CM. Mechanisms of vascular calcification in renal disease. Clin Nephrol 2005 Feb;63(2):146-57. DOI: $10.5414 /$ CNP63146

31. Schurgers LJ, Cranenburg EC, Vermeer C. Matrix Gla-protein: the calcification inhibitor in need of vitamin K. Thromb Haemost 2008 Oct;100(4):593-603.

32. Xiao DM, Wu Q, Fan WF, Ye XW, Niu JY, Gu Y.
Effect of serum FGF-23, MGP and fetuin-A on calcium-phosphate metabolism in maintenance hemodialysis patients. Hemodial Int 2013 Oct;17(4):483-492. DOI: $10.1111 /$ hdi.12033

33. Delanaye P, Krzesinski JM, Warling X, Moonen M, Smelten N, Medart L, et al. Dephosphorylated-uncarboxylated Matrix Gla protein concentration is predictive of vitamin $\mathrm{K}$ status and is correlated with vascular calcification in a cohort of hemodialysis patients. BMC Nephrol 2014 Sep 4;15:145-2369-15-145.

34. Aoun M, Makki M, Azar H, Matta H, Chelala DN. High Dephosphorylated-Uncarboxylated MGP in Hemodialysis patients: risk factors and response to vitamin K2, A pre-post intervention clinical trial. BMC Nephrol 2017 Jun 7;18(1):191-017-0609-3.

35. Isakova T, Wahl P, Vargas GS, Gutierrez OM, Scialla $\mathrm{J}$, Xie H, et al. Fibroblast growth factor 23 is elevated before parathyroid hormone and phosphate in chronic kidney disease. Kidney Int 2011 Jun;79(12):1370-8. DOI: $10.1038 / \mathrm{ki} .2011 .47$

36. Seiler S, Reichart B, Roth D, Seibert E, Fliser D, Heine GH. FGF-23 and future cardiovascular events in patients with chronic kidney disease before initiation of dialysis treatment. Nephrol Dial Transplant 2010 Dec;25(12):3983-9. DOI: 10.1093/ndt/gfq309

37. Kim HJ, Park M, Park HC, Jeong JC, Kim DK, Joo $\mathrm{KW}$, et al. Baseline FGF23 is Associated with Cardiovascular Outcome in Incident PD Patients. Perit Dial Int 2016 Jan-Feb;36(1):26-32. DOI: 10.3747/ pdi.2013.00343

38. Scialla JJ, Lau WL, Reilly MP, Isakova T, Yang HY, Crouthamel $\mathrm{MH}$, et al. Fibroblast growth factor 23 is not associated with and does not induce arterial calcification. Kidney Int 2013 Jun;83(6):1159-68. DOI: 10.1038/ki.2013.3

39. Moldovan D, Moldovan I, Rusu C, Kacso I, Patiu IM, Gherman-Caprioara M. FGF-23, vascular calcification, and cardiovascular diseases in chronic hemodialysis patients. Int Urol Nephrol 2014 Jan;46(1):121-8. DOI: $10.1007 / \mathrm{s} 11255-013-0422-2$

40. Zittermann A, Iodice S, Pilz S, Grant WB, Bagnardi V, Gandini S. Vitamin D deficiency and mortality risk in the general population: a meta-analysis of prospective cohort studies. Am J Clin Nutr 2012 Jan;95(1):91-100. DOI: 10.3945/ajen.111.014779

41. Zhang Y, Darssan D, Pascoe EM, Johnson DW, Pi H, Dong J. Vitamin D status and mortality risk among patients on dialysis: a systematic review and meta-analysis of observational studies. Nephrol Dial Transplant 2018 Feb 21. DOI: 10.1093/ndt/gfy016 